\title{
Study on the Talent Cultivation Under the Double-Class Construction of Colleges and Universities
}

\author{
Yinhong Wang1,a,* and Li Wan ${ }^{1}$ \\ ${ }^{1}$ Discipline Construction Office, China University of Geosciences, Beijing, China \\ ${ }^{\mathrm{a}}$ wyh@cugb.edu.cn \\ *corresponding author
}

Keywords: Double-Class, Talent Cultivation, Colleges and Universities, Countermeasures

\begin{abstract}
Double-class construction refers to the construction of the world-class universities and firstclass disciplines. Under the background of the double-class construction, the main tasks of colleges and universities include the talent cultivation, the scientific research, the social service, and the cultural inheritance. However, the most fundamental task of colleges and universities is to carry out the talent cultivation. In order to strengthen the talent cultivation and improve the quality of the talent cultivation in colleges and universities, especially higher universities of geosciences, authors analyze the main existing problems in the talent cultivation, and suggest that colleges and universities should establish the long-term development goal of the talent cultivation, control their own development scale, strengthen the construction of the teacher teams, properly handle the relationship between the teaching and the scientific research, and further enhance students' ideal faith education so as to promote their healthy and comprehensive development.
\end{abstract}

\section{Introduction}

Colleges and universities are the most active and creative academic palace and the origin of new ideas and new culture. The talents, who vigorously create and spread advanced productive forces and advanced culture, are valuable resources for social development. As a unique cultural institution with the functions of the teaching and scientific research, the talent cultivation should include two aspects under the background of double-class construction of colleges and universities: enhancing the teachers' ability of the scientific research and teaching to build a high level of teachers' team, and cultivating students' skill in practice and innovation so as to improve the quality of talent training.

In 2015, the State issued the general plan of promoting the first class disciplines and building the world-class universities, and it clearly put forward the construction task of talent cultivation: following the law of teacher' growth and development, optimizing the growth and development environment of young and middle-aged teachers, strengthening the ability of sustainable development of talent, cultivating good teacher teams with ideals and convictions, moral sentiments, solid knowledge and kindness. Attaching great importance to the moral character, regarding students' development as a starting point and a foothold, trying to cultivate all kinds of the innovative, applied and compound exceptional talents with a sense of the historical mission and social responsibility, innovative spirit and practical ability. Colleges and universities should enhance the devotion of talents training and attach importance to the role of talent cultivation because it is conducive to the cultivation of high quality talents in accordance with the needs of social development, and to enhance national competitiveness and overall strength, and it is beneficial to improve the national quality and education level and realize the transformation from the country of population and resources to the powerful country of human resources. In addition, it is helpful to strengthen our country's innovation ability and scientific research ability, and to lay a solid talent foundation for realizing the great rejuvenation of Chinese nation [1]. 


\section{Existing Problems In The Process Of Talent Cultivation}

In the state double-class construction plan, this indicates that it is very necessary to optimize the structure of the subject, clarify the direction of the subject, improve the efficiency of the talents training, and implement the connotation development of higher education was proposed. Under the background of double-class construction, the talent training of our country has made certain achievements, but there are still some problems. For example, the goal of talent cultivation is not clear enough and the developing idea trends to single; the development of teaching team need to be strengthened and the quality of teaching should be improved urgently; the cultivation mode need to change desperately to improve students' enthusiasm for learning [2]. These problems bring serious challenge to our country's higher education.

\subsection{The Goal of Talent Cultivation is Not Clear Enough and the Developing Idea Trends to Single}

With strong support from the government, the higher education has entered the stage of mass development. The number and scale of colleges and universities continue to expand and the number of students is increasing. However, there is no change and innovation in the mode of talent training and education system in colleges and universities, and the mode of talents training in most colleges and universities is now broadly in line with the research-oriented universities. In fact, in the higher education system of our country, only a few research universities should undertake the task of elite education, and most universities undertake the task of mass higher education. This diversity distribution depends on the proper positioning of colleges and universities [3].

Different types and directions of colleges and universities have formed their own characteristics and different directions of development, which can meet the objective requirements of mass higher education [4]. However, in the process of cultivating talents, some colleges and universities neglect the characteristic subject and cultural accumulation formed in the course of their long-term development, and the developing goal, level and type of talent training lack its own unique definition.

At present, colleges and universities should be organized into a multidisciplinary, comprehensive and research-oriented goals, and they should also carry out the undergraduate, master and doctoral education. Different types of colleges and universities are all developing towards elite mode of talent cultivation [5]. Then several poor consequences will come up. The demand for talent training is not strict, which leads to no improvement in educational quality. The similarities and lack of features for colleges and the overlapping of service functions have led to vicious competition among universities for high quality students, famous teachers and other resources. Limited educational resources are divided and abused and the type of talent cultivation can't meet the needs of the social development, which will cause the employment difficulties and even other social problems.

2.2 The Construction of Teaching Teams Need to Be Strengthened And the Quality of Teacher Teams Should Be Improved Urgently

At present, students have proliferated, but the number of teachers increase slowly in several higher universities. These high student-faculty ratios will lead that the size of some course classes is too large, and that this will seriously affect the quality of teaching in colleges and universities. Moreover, several college teachers, especially research university teachers, are not correctly handle the relationship between the scientific research and teaching, they primarily incline to the scientific research, writing paper. Therefore, this limited teaching input and the enthusiasm lack of the teaching work lead to the quality decrease of higher education.

Teaching quality is the lifeline of education, and it is the eternal theme of education continuous healthy development. If the quality of teaching is not raised, there is no point in doing more scientific research because it is not helpful to the talent cultivation and the long-term development in China. Why 
do teachers lack enthusiasm for teaching? It includes both the subjective and the objective reasons. At present, the objective reason is that the promotion and salary distribution system of the college teachers is mainly related to the scientific research, and this will encourage teachers to participate in the research projects, publishing papers so as to further enhance the influence of the higher universities, thus the teachers don't have much energy into the teaching work in colleges and universities. The subjective reason is that some teachers think that the scientific research is a person's interest, and can have the immediate effect, while the teaching needs long-term experience accumulations. Therefore, the teachers tend to focus on the scientific research work in colleges and universities.

\subsection{The Cultivation Mode Need to Be Modified And the Students' Enthusiasm For Learning Need to Be Improved Desperately}

In the ideal, the college students should have the ideal, positive, energetic, free and democratic and scientific critical spirit. In real life, several students have no ideal ambition, and they are full of confusion and indulgence in colleges and universities.

At present, the quality of talent training has been greatly improved in the course of the discipline construction, but there are also some problems. The regular education mode has restricted the imagination interest and enthusiasm of students for learning. The theoretical and practical education is out of touch. Colleges and universities pay attention to theory education, while the investment of practice education is relatively insufficiency. Attaching importance to scientific education and light humanistic education, many colleges and universities have compulsory courses in politics, English and mathematics, but there are no compulsory courses for Chinese. Only the students, who are major in humanities or history, have Chinese lessons. Humanities education and science education are equally important to students' growth. In the process of cultivating talents, colleges and universities should take the students as the center, let them enjoy the maximum autonomy and initiative in their studies, give full play to their potential and expertise, and improve their enthusiasm for learning [6].

\section{Countermeasures}

Talent training is the primary task of higher education. The quality of talent training determines the level of higher education. Improving the quality and efficiency of personnel training is very helpful to make full use of educational resources and to realize the connotative development of education in colleges and universities. In view of the existing problems in the process of talent training, authors provide some suggestions and countermeasures. For colleges and universities, it is very necessary to identify the target, control the development scale, and take a connotative way of development. Strengthen the construction of teaching staff and properly handle the relationship between teaching and scientific research. Take the student as a center, change the development mode of education, and further promote the comprehensive development of the students.

\subsection{Identify the Target, Control the Scale of Development and Take a Connotative Way of Development}

The goal of cultivating talents embodies the specific requirements of the training of higher education talents in colleges and universities, and the rational orientation of the talent training will help confirm the guiding ideology and enhance the core competitive advantage [7].

Colleges and universities should take full accounts of the cultural accumulation and characteristics, the requirements of economic and social development, and the quality and ability of the students, identify the direction of talents training, and set up a reasonable training target. Different levels and types of colleges and universities should have different talent cultivation mode, talent cultivation path, and talent cultivation concept. Not all colleges and universities develop the research-oriented universities, but they should focus on the first-class development goals in their respective fields. If we pursue a unilateral high- 
level talent training in colleges and universities, this will lead to the imbalance of social talents structure. However, the structural surplus of talent supply has aggravated the difficulty of college graduates' employment in colleges and universities [8].

Moreover, colleges and universities should properly control the scale of the development and do not blindly seek for perfection and comprehensive. Improving the requirements of talent training is helpful to promote the quality of talent training, and to take the development road of higher education connotative.

\subsection{Strengthen the Construction of Teaching Staff and Properly Handle the Relationship Between} the Teaching and the Scientific Research.

College teachers are the main practitioners of the talent cultivation in colleges and universities, and they guide the students to the temple of knowledge. A high level of teachers' team is the guarantee of improving the quality of personnel training. Under the background of double-class construction, colleges and universities, especially higher universities of geosciences, should increase investment of education, and introduce and employ excellent teachers actively to enrich the teaching staff. In recent years, China University of Geosciences (Beijing) (CUGB) has adopted many methods to strengthen their own construction of the teaching staff, and have made a series of breakthrough and new achievement in the field of the science and technology and that the comprehensive competitiveness of CUGB has experienced a continuous increase. Firstly, CUGB has conducted 499 research projects funded by the National Natural Science Foundation of China, with a tendency of from 72 projects in 2011 to 92 projects in 2017. Secondly, the level and quality of science and technology achievements is unceasingly improved. CUGB has published 4418 SCI papers including 3703 foreign periodicals SCI papers with a great increasing trend from 2011 to 2017. Thirdly, CUGB has gained more and more science and technology awards. The number of State Science and Technology Awards amounts to 8 while the number of Province (or Ministry) Science and Technology Awards amounts to 66 from 2011 to 2017. Therefore, the academic achievements made by CUGB in recent 7 years are remarkable.

Additionally, it is also necessary for higher universities to innovate the management system and teaching assessment system, perfect the system of salary distribution, and improve the enthusiasm and initiative of teachers' teaching. The college teachers undertake the task of the scientific research and teaching at the same time, however, how do they coordinate the relationship between the teaching and scientific research correctly, this not only determines whether the university can better play its value, but also is related to the legitimacy of university existence and accreditation of teachers' identity in colleges and universities [9]. Research shows that the relationship of teaching and scientific research are positively related, so we can't separate the scientific research and teaching artificially, several teachers may be specialized in teaching, and others may concentrate on the scientific research.

Colleges and universities should allocate the teaching and research tasks appropriately according to their scientific research ability, teaching experience and interest. The young innovative teachers should focus on the scientific research and arrange some teaching work appropriately, and accumulate the experience of teaching[10]. The elder teachers are rich in experience of teaching and working, and they should focus on education work in order to stimulate students' interest and lead students into the hall of knowledge. Colleges and universities need to be rational about the first-class goal-driven and be committed to formulate the reasonable evaluation and assessment mechanism and the scientific way of teaching management, promote the benign development of the relationship between the teaching and scientific research, improve the quality of the talent training and enhance the influence of the school. This is the only way that we can really improve the strength and popularity of colleges and universities. It is unwise to blindly pursue the improvement of scientific research ability on the surface.

3.3 Take the Student as a Center, Change the Development Mode of Education and Promote the Comprehensive Development of Students 
Young vigorous students are an important reserve force for national development, and are also a national talent pool and a source of innovation. Colleges and universities should focus on students in the process of cultivating talents, explore and create education culture mode, and fully mobilize the autonomy and initiative of students under the background of double-class construction.

In addition, it's indispensable to increase the input of education and cultivate the practical ability of students so as to help them better understand and apply theoretical knowledge and to promote the balanced development of theory education and practice education. The intersection of science education and humanistic education which we are supposed to attach great importance to is the tendency of the development of the education, and it is also the inevitable outcome of the development of science, technology and society[11, 12].

The combination of logical thinking and abstract thinking is an important way to cultivate students' innovative ability. In a word, the school should transform education training mode, promote the all-round development of students, and cultivate students to become outstanding talents with humanistic spirit and scientific spirit, innovative spirit and practical ability.

\section{Conclusions}

For colleges and universities, the talent cultivation is the most fundamental mission, and improving the quality of the talent cultivation is the eternal theme of the education development. Under the background of double-class construction, colleges and universities should focus on these basic objectives and tasks of the talent cultivation, confirm the development goal of the talent cultivation, strengthen the group construction of teachers and researchers, create a good work environment, promote the balanced development between the humanistic education and the science education, and further promote the students' comprehensive development so as to improve completely the quality of the talent cultivation.

\section{References}

[1] Y.H. Wang, "Discussion on reform and innovation of scientific and technological management in higher universities at new stage", Chinese Geological Education. no. 1, pp. 98-101, 2007.

[2] Y.H. Wang, L. Wan, X.H. Lei, "Countermeasures and suggestions for improving management of science and technology achievements in higher universities of geosciences at new stage", International Conference on Economic and Information management. pp.67-70, 2011.

[3] Y.H. Wang, L. Wan, R.S. Ji, "Statistical analysis of SCI papers published by China University of Geosciences(Beijing)", Bulletin of National Natural Science Foundation of China. no.2, pp.153-156, 2014.

[4] M.Y. Pan, "The educational quality view of the popularization of higher education", Jiangsu Higher Education. no.1, pp.6 9, 2007.

[5] X.J. Liu, "On the identity of higher education institutions", Journal of Higher Education. vol. 24, pp. 24-28, 2003.

[6] X.P. Zhang, "An analysis of the training mode of innovative talents in American universities", China University Teaching. no.3, pp.7-11, 2006.

[7] Y.X. Wei, "Rational orientation of training objectives in Colleges and universities from the perspective of talent type", Education and Vocation. no.6, pp.12-17, 2010.

[8] J. Deng, "Taking the lead of discipline construction and promoting the core competence of the university", Chinese Geological Education. no. 4, pp. 10-12, 2012.

[9] X.J. Liu, J.C. Zhang, H.F. Wu, “A survey on the teachers' understanding and management of the relationship between teaching and research", Research in Higher Education of Engineering. no.2, pp.3542, 2010.

[10] Y.Q. Zhou, "Challenge the situation of attaching importance to science and despising the liberal 
arts: Promoting the integration of humanistic education and scientific education", China Higher Education Research, no.1, pp.11-12, 2002.

[11] J. Deng, B.S. Yu, F. Li, Y. Qin, "The key to enhance core competitiveness of a university: Top design and institutional Innovation", no. 1, pp. 1-3, 2014.

[12] Y.H. Wang, L. Wan, X.H. Lei, "A brief discussion on how to construct the scientific and technological platforms in colleges and universities, International Conference on Economic and Information management", pp. 62-66, 2011. 